\title{
Bioética empírica e moral craft
}

\author{
Joaquim Clotet
}

Pontifícia Universidade Católica do Rio Grande do Sul, Porto Alegre/RS, Brasil.

\section{Resumo}

Neste ensaio são examinados os conceitos de bioética empírica e moral craft segundo Michael Parker. A bioética fundamentada em princípios puramente teóricos mostra-se incapaz de resolver adequadamente conflitos de cunho ético, e a moral só pode ser compreendida no contexto real em que as pessoas vivem. Ambos os axiomas motivam, entre outros, o surgimento da bioética empírica, fundamentada em dados etnográficos, demográficos, de ciências sociais e empíricos. Trata-se de aprender e de resolver conflitos por meio do exercício diário, dos êxitos e erros, de soluções que foram adquiridas e validadas na prática. Moral craft é o conjunto de princípios e valores morais elaborado de forma individual ou coletiva, imprescindíveis para a análise, o estudo e a pesquisa de um caso ou problema. 0 moral craft como apresentado por Parker revela o caráter que aperfeiçoa a ética empirista.

Palavras-chave: Ética. Bioética. Empirismo.

\section{Resumen}

\section{Bioética empírica y moral craft}

En este ensayo se examinan los conceptos de bioética empírica y moral craft según Michael Parker. La bioética fundamentada tan solo en principios teóricos es incapaz de resolver adecuadamente conflictos de carácter ético, y la moral únicamente puede ser comprendida en el contexto real de las personas. Ambos axiomas motivan, entre otros, el surgimiento de la bioética empírica, basada en datos de las ciencias etnográficas, demográficas, sociales y empíricas. Se trata de aprender y resolver conflictos a través del ejercicio diario, aciertos y errores, soluciones adquiridas y validadas en la práctica. Moral craft es el conjunto de principios y valores morales elaborado de forma individual o colectiva, imprescindibles para el análisis, estudio e investigación de un caso o problema. El moral craft, tal como presentado por Parker, manifiesta el carácter que perfecciona la ética empirista.

Palabras clave: Ética. Bioética. Empirismo.

\section{Abstract}

\section{Empirical bioethics and moral craft}

This study discusses Michael Parker's concepts of empirical bioethics and moral craft. Bioethics grounded only on theoretical principles cannot properly resolve ethical conflicts, and morals can only be understood in the real contexts in which people live. Both axioms, among others, have led to the development of empirical bioethics, based on ethnography, demography, social sciences and empirical data. It aims to explore and resolve ethical dilemmas by using facts, daily practice, success and failure, and solutions acquired and validated in practice. Moral craft is a set of moral and theoretical principles and values, individually or collectively built, for the analysis, study or research of a case or problem. Moral craft, according to Michael Parker, reveals the character that perfects empiricist ethics.

Keywords: Ethics. Bioethics. Empiricism. 


\section{Ética e ética aplicada}

O conceito de bioética empírica chamou minha atenção a partir da leitura do livro Ethical problems and genetics practice ${ }^{1}$ e dos diálogos com seu autor, o professor Michael Parker. A obra, ainda que dirigida principalmente aos profissionais da genética, interessou-me especialmente por reunir ideias e interpretações para mim pouco frequentes em um texto de ética e bioética. Considero por isso apropriado iniciar este ensaio com breve comentário sobre os conceitos de "ética", "ética aplicada" e "bioética", que antecedem e introduzem significativamente o de "bioética empírica".

Tentar definir a ética é empreendimento pouco menos que impossível. Cortina e Martínez, porém, a definem de forma genérica com clareza e brevidade: ética entendida como parte da filosofia que se dedica à reflexão sobre a moral ${ }^{2}$. Sua relevância não é novidade, pois se trata de tema intimamente enraizado no ser humano, em sua vida, suas aspirações e decisões individuais e coletivas, sejam elas familiares, profissionais, políticas, esportivas ou ambientais.

A extensa gama de concepções filosóficas mediadas pela cultura, economia, política, religião, mídia, pelo meio ambiente, pela ciência e tecnologia - constitui um conglomerado polimórfico de conceitos, atitudes e valores passíveis de interpretações e condutas diversas. Há, no entanto, elemento primordial ou eixo neural que a estrutura e a dinamiza: o ser humano, o sujeito, o eu, o homem ou a mulher, o masculino ou o feminino. Dificultam a compreensão desses conceitos, porém, afirmações desconcertantes como a de Stephen Hawking: nós somos mera poeira estelar ${ }^{3}$.

No paulatino progresso físico e psíquico do ser humano, surge uma série de interrogações. Uma delas, manifestada explícita ou implicitamente, expoente do amadurecimento racional e emocional, é a pergunta sobre o que é bom ${ }^{4}$, e primordialmente, desde a metaética, a questão da definição ${ }^{5}$. Ultrapassando o tema do significado, Wittgenstein ${ }^{6}$, ciente das diversas interpretações da ética ao longo da história da filosofia, da sua relação com as humanidades e da carência de dados objetivos e numéricos, a descreve como tendência ou inclinação do ser humano ao bem-estar, à justiça, à amizade, ao respeito, à paz etc., que nunca iria ridicularizar nem desrespeitar.
Ao aprofundar o mesmo tema, é fácil perceber que certas perguntas suscitam dúvidas e desconfiança. Existe uma única resposta aos questionamentos éticos? Os princípios da ética estão condicionados à própria pessoa, à cultura ou à educação? Assim sendo, o ceticismo ou o relativismo são os melhores posicionamentos perante os valores humanos? Questionamentos análogos, relacionados com a ética normativa e a ética descritiva, ocuparam numerosos pensadores ao longo dos séculos. Esta reflexão, acrescida, continua na atualidade.

Imersa nos temas antropológicos, epistêmicos e metaéticos da história da filosofia e mais concretamente da ética, surge de forma explícita e progressiva a ética aplicada, também denominada "ética prática" 7 . Esta refere-se a enunciados próprios da ética normativa sobre ações singulares da vida individual ou coletiva (como a opção pelo estado sedativo permanente), profissional (por exemplo, a ética empresarial), social (como a discriminação em razão do gênero) e internacional (como a questão dos refugiados) ${ }^{8}$. De forma sintética, Singer a define como a aplicação da ética ou moralidade a problemas práticos 9 . Mais recentemente, McMillan a introduz como a ênfase em tentar propor soluções a questões morais de ordem prática ${ }^{10}$. Não se trata de uma novidade, pois os filósofos têm se dedicado sempre a problemas relevantes, e às vezes urgentes, da vida prática, tal como fizeram, a respeito do suicídio, Sêneca ${ }^{11}$ e Hume ${ }^{12} \mathrm{e}$, em problemas mais abrangentes, Russell ${ }^{13}$.

A ética, e de modo especial a ética aplicada, estende sua projeção e seu conteúdo desde os alvores do século XX para a ciência, a sociedade e o universo. Resulta evidente que o desenvolvimento científico, tecnológico e social precisava de um locus para harmonizar as ciências da vida com especial ênfase à ecologia, às ciências tecnológicas e ao progresso - com os valores individuais, sociais e globais, de forma a considerá-los necessariamente inseparáveis, quase visando à utopia.

A tecnologia deveria progredir em consonância com o bem-estar social, incluindo, em nossos dias, o meio ambiente e a contenção do ameaçador aquecimento global. Como clamam os ativistas ambientais, temos que refrear nossa emissão de gases do efeito estufa ${ }^{14}$; e quanto mais carbono você emite, maior é o seu dever moral ${ }^{15}$. Não sendo assim, seria previsível um fracasso universal, que lamentavelmente também afetaria o 
florescimento humano ${ }^{16}$. Deve-se reconhecer que desde o início da Revolução Industrial a humanidade tem uma dívida econômica e moral que só aumentou ao longo dos séculos ${ }^{17}$.

\section{Bioética}

Ante a problemática e os desafios apresentados anteriormente, Paul Max Fritz Jahr criou o termo "bio-ethik" em $1927^{18}$, e Van Rensselaer Potter estabeleceu "bioethics" em $1971^{19}$. O campo da bioética se difundiu em âmbito internacional e continua sendo fecundo e insubstituível para o desenvolvimento da sociedade, dados os desafios imprevisíveis do futuro próximo ${ }^{20}$.

Não há consenso entre os autores sobre a bioética ser uma ética aplicada ${ }^{21}$ : alguns a subordinam a esse campo e outros a declaram independente ${ }^{22}$. Ambos os posicionamentos, porém, confirmam a interdisciplinaridade e a pluralidade de perspectivas e métodos, sendo possível afirmar que se trata de uma macroética ${ }^{23}$, que há diversas bioéticas ${ }^{24} \mathrm{e}$ que esta é uma disciplina hibrida ${ }^{25}$. Estas diferenças justificam-se em parte pelo fato de que desde seu início a bioética reuniu cientistas e filósofos, havendo, posteriormente, marcante presença de profissionais das áreas da saúde, abrindo-se finalmente à sociedade global, sendo essa uma preocupação desde seus primórdios.

\section{Bioética empírica}

As definições da bioética também evoluíram ${ }^{26}$. A sociologia, o direito, as ciências, a etnografia e o interesse pela objetividade adquiriram maior relevância. Estas especialidades abriram o horizonte para uma bioética mais focada na prática, mais acurada e mais abrangente. Os dados quantitativos e as informações singulares de casos vividos foram considerados prioritários para estudos, pesquisas e a tomada de decisões. A epistemologia, sem relegar a teoria, considerou imprescindível uma maior aproximação aos aspectos experimentais ou sensíveis.

A política, a esfera pública, os conflitos entre as tradições disciplinares, a diversidade, os aspectos singulares ou diferenciais das pessoas (se pacientes, familiares ou profissionais, de que região provêm, em que país vivem etc.) influíram principalmente para diferenciar a bioética até aqui tratada da bioética que considera relevantes as informações que envolvem cada questão ou problema. Esta é a denominada "bioética empírica".

Têm sido objeto de especial atenção na obra de Parker ${ }^{1}$ alguns comentários e definições que perfilam uma visão original e diferenciada da ética e da bioética. Elenco a seguir algumas das afirmações que considero relevantes, concernentes a moralidade, ética, bioética, bioética empírica, etnografia e moral craft:

A moralidade somente faz sentido no contexto de práticas e valores compartilhados $e$ estabelecidos ${ }^{27}$.

Tenho observado e tentado rastrear problemas éticos conforme emergiam e se transformavam (...) meu papel está profundamente implicado no exercício da ética nesse contexto ${ }^{28}$.

A bioética falha ao não considerar suficientemente o significado moral das realidades nas quais as pessoas - pacientes, familiares e médicos - vivem e trabalham ${ }^{29}$.

Quase desde seu surgimento tem se reivindicado que a bioética se baseie mais em dados empíricos, e que o papel do empirismo seja mais enfatizado na deliberação bioética ${ }^{30}$.

A etnografia possibilita que a bioética entenda melhor o significado e a importância intersubjetiva da situação em análise ${ }^{29}$.

Um experiente profissional geneticista comprometido com o moral craft percebe uma regra importante e vital em sua prática para uma interação ativa e produtiva entre moral e ética ${ }^{31}$.

Essas declarações constituem, sob minha ótica, o âmago de uma esclarecedora e construtiva visão de bioética, e a expressão giro empírico da bioética $^{32}$ confirma este posicionamento. As afirmações anteriores podem ser assim resumidas: a moral só pode ser compreendida no contexto real em que as pessoas vivem; a ética e a bioética precisam ser instruídas pela moral; a eticidade de determinado ato, processo ou caso precisa inexoravelmente de dados individuais, informações etnográficas e de avaliação moral à margem de ditames previamente estabelecidos, o que não implica necessariamente o seu desconhecimento ou exclusão. 
Com base nas afirmações e na síntese apresentadas, cabe dizer que a concentrada declaração empírica da bioética possibilita enunciar alguns axiomas para sua compreensão e seu desenvolvimento. Resulta evidente que a bioética empírica transcende os limites disciplinares da ética e da bioética, priorizando fatos à teoria. A maioria dos casos e debates sobre bioética envolve dados empíricos inquestionáveis ${ }^{32}$.

A bioética fundamentada apenas em princípios teóricos mostra-se incapaz de resolver adequadamente conflitos de cunho ético. Da mesma forma, para ser eficiente, a bioética precisa abranger a realidade em suas múltiplas formas: individual, coletiva, familiar, profissional, sociológica, jurídica, acadêmica etc..$^{33}$ Igualmente, deve integrar métodos das humanidades, ciências sociais e ciências da vida, incluída a ecologia. A sinergia entre esses campos gera uma nova perspectiva, ampliando a bioética.

Cabe reconhecer entre as ciências sociais a função destacada da sociologia: a bioética empírica deve saber associar argumentos e valores com a realidade do contexto social ou familiar por meio de pesquisa adequadamente construída e realizada. Essa inter-relação é também denominada "deliberação democrática" e "democracia deliberativa" em estudos ou discussão de casos em que participam pesquisadores, profissionais e representantes da sociedade ${ }^{34}$.

Conforme o exposto, a bioética empírica subordina o conhecimento à experiência (empeiria), ao modo do empirismo inglês, que considera indispensáveis os dados proporcionados pelos sentidos. Assim, experiências e informações objetivas possibilitam e aperfeiçoam a compreensão dos temas, questões ou problemas apresentados.

A aproximação à realidade amplia e enriquece o significado e o desenvolvimento da bioética. Neste aspecto, a etnografia é considerada método insubstituível para identificar e compreender as características singulares ${ }^{35}$ que condicionam e influenciam modos de agir, decisões e valores ${ }^{33}$. Portanto, merece atenção especial o entorno ou contexto social em que os problemas, casos ou conflitos acontecem. Além disso, a etnografia vem a ser a condição sine qua non para o caso a ser examinado e decidido.

Desse modo, a bioética não fica à margem da experiência, como tradicionalmente acontece na ética filosófica. O seu desenvolvimento é paulatino, monitorado e desafiado por novos casos ou problemas que podem contribuir, dado seu caráter empírico, para o progresso e a melhoria do conhecimento em casos subsequentes ${ }^{36}$. Reconhecer o valor do empirismo no desenvolvimento da bioética, como visto, implica a aproximação ao dia a dia das pessoas, a interação entre cidadãos e especialistas das mais diversas áreas - o que a diferencia significativamente da bioética primeira ${ }^{1}$.

A etnografia como campo que procura e reúne dados específicos da vida social em situações diferenciadas transforma-se em aprimorada ferramenta de pesquisa que contribui para a interação entre as ciências sociais e a ética, cooperando para uma nova dimensão da bioética. Desse modo, a bioética empírica - superando visões anteriores, mas não menos relevantes - amplia o conhecimento, a prática e a responsabilidade global.

\section{Moral craft}

Deixando à margem nesta ocasião o exame pormenorizado de alguns dos conceitos mais representativos da bioética empírica, centrarei minha atenção na expressão "moral craft", utilizada por Parker ${ }^{37}$, que despertou meu interesse pelo seu caráter inusitado no âmbito da ética.

A primeira imersão realizada foi semântica. O significado primigênio de "craft" refere-se a obra ou objeto elaborado por autor, técnico ou artista ${ }^{38}$. Parker ${ }^{37}$ usa o conceito a partir da perspectiva de Richard Sennett na obra The craftsman ${ }^{39}$. Para este autor, craftsmanship é a arte ou habilidade de construir ou desenvolver, a habilidade de fazer as coisas (...) por si mesmas ${ }^{40}$. Por outro lado, o artesão [craftsman] constantemente enfrenta padrões objetivos de excelência discrepantes ${ }^{40}$. Além disso, todo bom artesão conduz um diálogo entre prática concreta e pensamento ${ }^{40}$.

Parker ${ }^{37}$ prescinde de uma definição concisa e objetiva do moral craft, o que dificulta a compreensão precisa do termo. Em razão dessa omissão, a partir do conceito de ética nesse contexto, citarei outros cinco termos que expressam algumas características que o configuram e, por conseguinte, os traços que o diferenciam. 
Sabedoria prática

\author{
Sabedoria prática do professional \\ geneticista experiente comprometido com o \\ moral craft em genética ${ }^{31}$.
}

O autor equivale sabedoria prática ao termo "phronesis" 41 , a virtude dianoética da sabedoria prática, diferente da sabedoria teórica (sophia) e da técnica (techne), arte ou craft. Techne, neste caso craft, indica a série de procedimentos que visam produzir determinado resultado. Trata-se da virtude da inteligência poética ou construtiva (episteme poietike), que se diferencia da ciência da inteligência teórica (episteme dianoetike) e da episteme praktike, que considera os atos humanos ${ }^{42}$.

Parker repara também na boa prática, que requer não só que seja dada atenção aos aspectos clínicos ou médicos da rotina profissional com pacientes e familiares, mas também ao que pode ser considerado o moral craft em genética ${ }^{43}$. Com essa afirmação, o autor reconhece a composição do moral craft, episteme poietike e episteme praktike, que opera após eleição (proairesis) cujo resultado será o julgamento da ação como boa ou má.

\section{Moral viva ou moral vivida}

Um tipo de engajamento com a prática que possibilita que tanto ética quanto a moral sejam levadas a sério ${ }^{31}$.

O interesse pelo aperfeiçoamento da moral e pela bioética empírica nasce também do desejo de dar nova vida e novo impulso à bioética tradicional. Trata-se de aprender e de resolver dilemas por meio do factual, da prática diária, dos êxitos e dos erros, de soluções adquiridas e validadas na prática, e não em uma aula teórica ou em obra recém-publicada. Esta é uma bioética experimentada e garantida no mundo real pela responsabilidade e pela eficiência individual e corporativa.

\section{Comprometimento}

Comprometimento com o trabalho moral (...). (...) o profissional geneticista que participa do Genethics Club compartilha o profundo compromisso de desempenhar bem suas funções e reconhece que isso requer um comprometimento não só com boas práticas nos aspectos médicos de seu exercício profissional diário, mas também com o que chamei de "moral craft" em genética ${ }^{44}$.

Direta ou indiretamente, o compromisso está relacionado à ética e à denominada "ética diária" ou "ética cotidiana", entendida como ética aplicada ${ }^{45}$. O compromisso do profissional de genética com o moral craft pode ser entendido também como a atuação conforme o código de ética, comprometimento profissional com o moral craft em genética ${ }^{46}$.

\section{Habilidades}

Reconhece o valor de desenvolver habilidades como deliberação moral e reflexão crítica, assim como as habilidades ou julgamento moral associados com o moral craftsmanship, e busca oportunidades para testar e desafiar essas habilidades ${ }^{46}$.

O espaço ideal para a aprendizagem das habilidades morais citadas e a educação continuada é o Genethics Club, ou o fórum de profissionais de genética (pesquisadores, clínicos, enfermeiros, técnicos, estudantes) e de bioética. O colóquio é seu método de trabalho. Uma de suas prioridades é descobrir métodos de aproximação ao caso ou problema estudado, desde óticas até posicionamentos diferentes, salientando os dados e pormenores que o identificam e o diferenciam.

O diálogo entre profissionais e a multidisciplinaridade, com responsabilidades diversificadas, constituem condições inigualáveis para o exercício e a aprendizagem contínua das habilidades necessárias para a prática correta da profissão. Isso é exemplo da denominada bioética empírica dialógica ${ }^{47}$. Lickona ${ }^{48}$ afirma que a teoria e a prática são indissociáveis para uma formação adequada e sempre em desenvolvimento.

\section{Procura de problemas}

Comprometimento com o trabalho moral da procura de problemas ${ }^{31}$.

Pesquisadores da bioética empírica estão compromissados com o "moral craft" para empreender novas formas de pesquisa bioética, administrando dificuldades e incertezas emergentes enquanto lidam 
com padrões disciplinares estáveis em sua pesquisa, buscando elaborar argumentos éticos que tenham formas novase criativas de caráter prático ${ }^{49}$.

Essa é uma característica que diferencia a bioética empírica das atividades do Genethics Club, à qual se concede particular importância ou consideração. A procura de problemas está no cerne do moral craft em genética ${ }^{46}$. Consiste na busca de novos métodos de pesquisa para casos considerados singulares, especiais ou difíceis de identificar e de resolver.

Os casos comuns, apresentados para análise ou diagnóstico, são conduzidos com métodos próprios. Os interlocutores do Genethics Club, defensores da bioética empírica, esforçam-se para procurar e construir novos e combinados métodos de pesquisa, reavaliando problemas e soluções de caráter ético e epistemológico para obter resultados mais eficientes, contribuindo desse modo para o progresso e aperfeiçoamento da bioética empírica.

É o meu parecer que moral craft pode ser entendido como o construto e o repositório moral próprio ou individual que pode, contudo, ser compreendido como coletivo, realizado por profissionais engajados e hábeis na deliberação e no diálogo para o descobrimento de novos métodos, soluções e valores relativos ao exercício profissional. A explanação de Parker ${ }^{37}$ ao longo da obra é, porém, um tanto indefinida a respeito desse duplo significado. É importante considerar que esse conjunto de valores deve ser referido à práxis, pois se trata de uma moralidade viva que acompanha e é decisiva nas atividades do dia a dia ou no exercício correto da profissão ${ }^{37}$.

Resulta evidente, portanto, a estimável cooperação do Genethics Club para a construção do moral craft. Este modus operandi mostra também a relevância da bioética empírica, dado que dúvidas e conflitos decorrentes do exercício diário da medicina sustentam e alimentam o estudo e a discussão ${ }^{1}$. É possível considerar que a descrição pormenorizada dos dados, insubstituível na elaboração do moral craft, é semelhante à ética de situação, que considera de modo aproximado o contexto real de um fato, problema ou decisão. O moral craft, porém, reúne o maior número possível de dados a serem examinados e entendidos segundo critérios diferentes dos dessa vertente.
A ética de situação, centrada na pessoa, examina o contexto particular de um ato e prioriza como critério de escolha o amor ${ }^{50}$, entendido como bem absoluto ao qual estão subordinados todos os valores ${ }^{51}$ - apenas uma coisa é intrinsecamente boa, o amor, um amor universal: nada mais ${ }^{52}$. É impossível, na construção do moral craft, adotar um só modelo de ética, de princípios ou de regras universais para avaliar ou solucionar um caso ou problema, como seria o reconhecimento da ética utilitarista enquanto único critério de conduta.

Apesar das diferenças, o moral craft e a ética de situação têm em comum uma thésis, ou princípio, polêmica para eticistas e juristas. Para Fletcher ${ }^{51}$, atos comumente considerados reprováveis podem ser julgados moralmente corretos, dependendo das circunstâncias, da intenção, da vontade e da emoção dos atores: há momentos em que o homem deve deixar seus princípios de lado e fazer a coisa certa ${ }^{53}$. (...) Todo homem deve decidir por si mesmo segundo sua própria avaliação das condições e consequências ${ }^{54}$. Esse modelo de ética, atrativo mas controverso, tem sido apresentado por alguns autores da filosofia existencialista e, de modo especial, na medicina moral por Joseph Fletcher.

$\mathrm{Na}$ ética empírica, um caso ou uma ação só pode ser moral e equitativamente avaliado examinando-se as características, os dados ou os detalhes que o revelam, esclarecem e justificam. O resultado do julgamento ou apreciação poderá ter caráter provisório, dada a possível mudança ou desvio por causa do empirismo dos dados, dos objetos ou das informações avaliadas. O moral craft, como apresentado por Parker ${ }^{37}$, revela desse modo o caráter que enriquece e aperfeiçoa a ética moldada pelo empirismo, de notável presença na pesquisa e no desenvolvimento da ciência e da tecnologia.

\section{Considerações finais}

O giro empírico da bioética, neste caso sob o impulso de Michael Parker ${ }^{1}$, é indiscutível. A bioética empírica apresenta na obra examinada características de uma ética plural em desenvolvimento, com ênfase na singularidade e relevância dos dados, bem como na epistemologia. Mostra-se uma bioética aplicada, já que se ocupa de atitudes e decisões a serem tomadas na pesquisa e no exercício da profissão, e nesta 
circunstância na área da saúde; normativa, visto que responde às perguntas "o que deveríamos fazer?" e "quem deveríamos ser?"; descritiva, pois examina ou analisa deliberações e ações a partir de diversos critérios; metaética, porque trata de questões epistemológicas e linguísticas.

A bioética empírica opera com a pesquisa qualitativa e desenvolve ideias e hipóteses para a pesquisa quantitativa, priorizando dados objetivos e numéricos, e pretende entender os aspectos individuais específicos em lugar de generalizá-los ou universalizá-los. O progressivo e reconhecido desempenho da bioética empírica a contrapõe à paralisia e à esterilidade.

Cabe observar algumas restrições a essa vertente conforme o exposto na obra. O critério, motivo ou justificação de determinada alternativa ou ação relacionada a uma escala ou hierarquia de valores não é suficientemente explícito sem apontar ou indicar a priori que valor de excelência seria o referente para o julgamento do mérito. Tal posicionamento pode induzir facilmente ao subjetivismo e ao relativismo, desvio que, conforme Parker ${ }^{1}$, pode ser mensurado, discutido, avaliado e corrigido pelo Genethics Club, a quem, contudo, não é transferida responsabilidade alguma, pois esta deve ser assumida pelo autor da proposta ou da decisão.
O moral craft, construto e repositório moral individual ou coletivo, passível de interpretações diversas, carece de definição clara e objetiva que evite imprecisões ou equívocos na compreensão e no uso do termo. Considero iniludível, desse modo, uma questão: quem exerce a função de reflexão que diferencia o aprovado do reprovado, do tribunal interior ou do que é anterior ou posterior a uma convicção moral, ou seja, da consciência moral? Cabe reconhecer que esse conceito está ausente ou omitido. Trata-se, na minha opinião, de um vazio moral difícil de justificar, o que poderia ser interpretado como conceito subentendido, porém não mencionado nas diferentes descrições ou comentários realizados ao longo da obra. O aspecto epistemológico, relevante para o autor, não é examinado neste ensaio pois exigiria um estudo em separado, ainda por fazer.

O livro tem uma característica que merece ser considerada: é um experimentado e genuíno tratado de ética empírica, já clarividente no seu título Ethical problems and genetics practice, escrito por um reconhecido cientista. Contudo, dada a necessária e inseparável vinculação entre ética e genética, teria sido apropriada a colaboração ou inclusive a coautoria de um filósofo da moral. Sua relevância, porém, é inquestionável.

\section{Referências}

1. Parker M. Ethical problems and genetics practice. Cambridge: Cambridge University Press; 2012.

2. Cortina A, Martínez E. Ética. 6 a ed. São Paulo: Loyola; 2015. p. 9.

3. Hawking S. Brief answers to the big questions. London: John Murray; 2018. p. 183. Tradução livre.

4. Moore GE. Principia ethica. Cambridge: Cambridge University Press; 2000. p. 57. Tradução livre.

5. Moore GE. Op. cit.

6. Wittgenstein L. Lecture on ethics. Chichester: Wiley Blackwell; 2014.

7. Moore GE. Review: the origin of the knowledge of right and wrong. Int J Ethics [Internet]. 1903 [acesso 6 jan 2021];14(1):115-23. Disponível: https://bit.ly/3a7B047

8. Lippert-Rasmussen K, Archard D. Applied ethics. In: LaFollette H. International encyclopedia of ethics. Oxford: Wiley Blackwell; 2013. p. 320-35.

9. Singer P. Practical ethics. Cambridge: Cambridge University Press; 1991. p. 1. Tradução livre.

10. McMillan J. The methods of bioethics: an essay in meta-bioethics. Oxford: Oxford University Press; 2018. p. 9. Tradução livre.

11. Séneca. Epístolas morales a Lucilio. Madrid: Gredos; 1986.

12. Hume D. Unpublished essays. In: Hume D. The philosophical works: essays: moral, political and literary. Darmstadt: Weihert-Druck; 1992. v. 2, p. 399-461. 
13. Russell B. Human society in ethics and politics. London: George Allen \& Unwin; 1971.

14. Thunberg G. No one is too small to make a difference. London: Penguin; 2019. p. 21. Tradução livre.

15. Thunberg G. Op. cit. p. 24. Tradução livre.

16. Garland-Thomson R, Haybron DN, Evans JH. Part I: what is human flourishing? In: Parens E, Johnston J, editors. Human flourishing in an age of gene editing. Oxford: Oxford University Press; 2019. p. 15-61.

17. Wallace-Wells D. The uninhabitable earth: a story of the future. London: Penguin; 2019.

18. Goldim JR. Revisiting the beginning of bioethics: the contribution of Fritz Jahr (1927). Perspect Biol Med [Internet]. 2009 [acesso 6 jan 2021];52(3):377-80. DOI: 10.1353/pbm.0.0094

19. Potter VR. Bioethics, bridge to the future. Englewood Cliffs: Prentice-Hall; 1971.

20. Goldim JR. Núcleo interinstitucional de bioética. UFRGS/HCPA [Internet]. 2000 [acesso 6 jan 2021]. Disponível: https://bit.ly/36hR4Pn

21. Kuhse H, Schüklenk U, Singer P, editors. Bioethics: an anthology. $3^{\mathrm{a}}$ ed. Chichester: Wiley Blackwell; 2016.

22. McMillan J. Op. cit.

23. Cortina A, Martínez E. Op. cit.

24. Callahan D. Bioethics. In: Post SG, editor. Encyclopedia of bioethics. $3^{\text {a }}$ ed. New York: Macmillan; 2004. p. 278-87.

25. Kirkwood K. Empiricism, values, and bioethics. Am J Bioeth [Internet]. 2009 [acesso 6 jan 2021];9(6-7):91-2. p. 91. Tradução livre. DOI: $10.1080 / 15265160902874478$

26. Cribb A, Owens J. Embracing diversity in empirical bioethics. In: Ives J, Dunn M, Cribb A, editors. Empirical bioethics: theoretical and practical perspectives. Cambridge: Cambridge University Press; 2017. p. 103-22.

27. Parker M. Op. cit. p. 125. Tradução livre.

28. Parker M. Op. cit. p. 148. Tradução livre.

29. Parker M. Op. cit. p. 132. Tradução livre.

30. Parker M. Op. cit. p. 131. Tradução livre.

31. Parker M. Op. cit. p. 129. Tradução livre.

32. Borry P, Schotsmans P, Dierickx K. The birth of the empirical turn in bioethics. Bioethics [Internet]. 2005 [acesso 6 jan 2021];19(1):49-71. DOI: 10.1111/j.1467-8519.2005.00424.x

33. Jacoby L, Siminoff L. Introduction. In: Jacoby L, Siminoff LA, editors. Empirical methods for bioethics: a primer. Bingley: Emerald Group; 2007. p. 1-10. (Advances in Bioethics, v. 11).

34. Kim S. Theory and practice of democratic deliberation in bioethics research. In: Ives J, Dunn M, Cribb A, editors. Empirical bioethics: theoretical and practical perspectives. Cambridge: Cambridge University Press; 2017. p. 177-94.

35. Dancy J. Ethics without principles. In: Marshall R. Ethics at 3:AM: questions and answers on how to live well. New York: Oxford University Press; 2017. p. 32-41.

36. Shelton W. The role of empirical data in bioethics: a philosopher's view. In: Jacoby L, Siminoff LA, editors. Empirical methods for bioethics: a primer. Bingley: Emerald Group; 2007. p. 13-20.

37. Parker M. Moral craft. In: Parker M. Op. cit. p. 112-30.

38. Aristotelis. Ethica Nicomachea. New York: Oxford University Press; 1979.

39. Sennett R. The craftsman. New Haven: Yale University Press; 2008.

40. Sennett R. Op. cit. p. 8-9. Tradução livre.

41. Aristotelis. Op. cit. p. 1141b.

42. Tricot J. Introduction et notes. In: Aristote. Éthique à Nicomaque. Paris: Librairie Philosophique; 1979. p. 7-29.

43. Parker M. Op. cit. p. 12. Tradução livre.

44. Parker M. Op. cit. p. 129-30. Tradução livre.

45. Martin MW. Everyday morality: an introduction to applied ethics. $4^{\mathrm{a}}$ ed. Belmont: Cengage Learning; 2007.

46. Parker M. Op. cit. p. 128. Tradução livre. 
47. Landeweer E, Molewijk B, Widdershoven G. Moral improvement through interactive research: a practice example of dialogical empirical bioethics. In: Ives J, Dunn M, Cribb A, editors. Empirical bioethics: theoretical and practical perspectives. Cambridge: Cambridge University Press; 2017. p. 139-58.

48. Lickona T. What does moral psychology have to say to the teacher of ethics? In: Callahan S, Bok S, editors. Ethics teaching in higher education. New York: Plenum Press; 1980. p. 103-32.

49. Ives J, Dunn M, Cribb A. Practical perspectives: an introduction. In: Ives J, Dunn M, Cribb A, editors. Empirical bioethics: theoretical and practical perspectives. Cambridge: Cambridge University Press; 2017. p. 125-38. p. 135.

50. Novi testamenti: Biblia graeca et latina. $3^{\text {a }}$ ed. Madrid: Consejo Superior de Investigaciones Científicas; 1953.

51. Fletcher J. Situation ethics: the new morality. $2^{\mathrm{a}}$. ed. Louisville: Westminster John Knox Press; 1997.

52. Fletcher J. Op. cit. p. 68. Tradução livre.

53. Fletcher J. Op. cit. p. 13. Tradução livre.

54. Fletcher J. Op. cit. p. 37. Tradução livre. 